\title{
Surface composition and protein adsorption of polyurethane membrane
}

\author{
Shih-Liang Huang ${ }^{\text {a,* }}$, Cheng-Fang Ou ${ }^{a}$, Juin-Yih Lai ${ }^{b}$ \\ ${ }^{a}$ Chemical Engineering Department, National Chin-Yi Institute of Technology, Taichung, Taiwan 41111, Republic of China \\ ${ }^{\mathrm{b}}$ Chemical Engineering Department, Chung Yuan University, Chung Li, Taiwan 32023, Republic of China
}

Received 30 September 1998; received in revised form 5 February 1999; accepted 12 February 1999

\begin{abstract}
Membranes of uncomplexed polyurethanes (PUs) were prepared by hydroxyl-terminated polybutadiene (HTPB), 4,4'dicyclohexylmethane diisocyanate $\left(\mathrm{H}_{12} \mathrm{MDI}\right)$ and 1,4-butane diol (1,4-BD). While complexed PUs were prepared by using $N$ methyl diethanol (MDEA) as the chain extender of which the tertiary amines were complexed with cupric ions. Molar ratio of protein adsorption of fibrinogen to albumin (F/A molar ratio) on polymer surface was measured. The F/A molar ratio was affected by surface composition. The surface composition was identified by ESCA measurement and quantified by the absorption ratio of carbonyl group to butadiene group $(\mathrm{C}=\mathrm{O} / \mathrm{C}=\mathrm{C}$ ratio $)$ on the FTIR-ATR spectra. Low F/A molar ratio and high contact angle were found on these PUs. The F/A molar ratio was decreased by the increase of soft segment or $\mathrm{C}-\mathrm{H}$ bond dispersed on the surface. Frequency difference $(\Delta \nu)$ and shiftment, hydrogen bonding index (HBI) and glass transition temperature difference $\left(\Delta T_{\mathrm{g}}\right)$ as a measure of phase homogeneity and the average strength of interpolymer hydrogen bonds were utilized to study the change of surface composition and intermolecular interaction of the prepared PUs. The effect of hard segment content, cupric chloride content on the surface composition and F/A molar ratio were investigated. (C) 1999 Elsevier Science B.V. All rights reserved.
\end{abstract}

Keywords: Polyurethane; Protein adsorption; Complex; Hydroxyl-terminated polybutadiene

\section{Introduction}

When a polymer is dipped in blood, in a few seconds adsorption of biomolecules of cells (usually proteins) takes place. The surface of a polymer is then in direct contact with biological components. The passivation of a surface because of the presence of

*Corresponding author. Tel.: +886-4-3924505, ext. 7515; fax: +886-4-3926617. albumin on it is in contrast to the increased adhesion of biological cells (platelet, bacteria, etc.) in the presence of fibrinogen [1,2]. Protein adsorption on a polymer has been thought to be important for the adhesion of platelet and blood compatibility [3,4].

Protein adsorption depends greatly on the surface composition and morphology of the biomaterial. Biomaterials either with superhydrophobic or superhydrophilic surface show a lower protein adsorption rate [4]. A study of lower surface energy soft segment on the surface may be important for its application to the 
biomaterial field [5]. Hydroxyl-terminated polybutadiene (HTPB) has been used in this study because it possesses lower surface energy and may induce a superhydrophobic surface of polyurethane (PU) polymer. Subsequent changes in composition on the airpolymer interface of these PUs occurred because polymer chains at the air-polymer interface are in an unsymmetrical environment in comparison with that within the polymer [6].

There are many studies aimed at discussing the effect of surface composition on protein adsorption on a polymer. It is reported that albumin has thromboresistant ability whereas fibrinogen promotes platelet adhesion on a polymer surface [7]. PUs containing long linear alkyl main chains are able to adsorb albumin and preferentially exhibited an improved haemocompatibility [8]. And it is believed that the ability of a polymer surface to promote platelet adhesion and activation is correlated to the adsorbed or deposited concentration ratio of fibrinogen to albumin $[9,10]$.

This study attempted to prepare uncomplexed PUs with different hard segment content and complexed PUs with different cupric chloride content. The surface composition of these PUs were investigated by the change of $\mathrm{C}=\mathrm{O} / \mathrm{C}=\mathrm{C}$ ratio and measured by FTIRATR. ESCA analysis was used to determine whether the surface composition of PUs with polybutadiene as soft segment had the major parts of butadiene content [11]. The polarity of the polymer surface can be determined by contact angle measurement. The measurements of DSC and FTIR were used to identify the degree of complexation and morphology change. The $\mathrm{C}=\mathrm{O} / \mathrm{C}=\mathrm{C}$ ratio, IR frequency difference and shift and glass transition temperature difference were used for the identification of surface composition and phase homogeneity and for the effect on the fibrinogen to albumin (F/A) adsorption molar ratio of these PUs.

\section{Experimental}

\subsection{Materials}

The chemicals used in this study were 4,4'-dicyclohexylmethane diisocyanate $\left(\mathrm{H}_{12} \mathrm{MDI}\right.$, Desmodur $\mathrm{W}$ of Mobay), hydroxyl-terminated polybutadiene (equivalent weight of 1333 with an approximate $60 \mathrm{wt} . \%$ of trans $-1,4,20 \mathrm{wt} . \%$ of cis-1,4 and 20 wt. $\%$ of vinyl-1,2, R-45M of ARCO). 1,4-Butane diol (1,4-BD) and $N$-methyldiethanolamine (MDEA) were used as chain extender for uncomplexed and complexed PUs, respectively. Dibutyltin dilaurate (DBTDL) was used as catalyst and cupric chloride as the complexation reagent. Toluene and dimethylformamide (DMF) were used as solvents. Polyols of PPG (polyoxypropylene glycol) and PBA (polybutylene adipate glycol) of M.W. 2000 were used for the preparation of PUs also. Fibrinogen from human plasma (M.W. 341000) and albumin from human serum (M.W. 68000) (Sigma) were used. Sodium citrate, sodium phosphate and sodium chloride (Merck) were used for the preparation of CPBS buffer solution. Triton X-100 and dodecyl sodium sulfate and sodium hydroxide were used for the preparation of desorbed solution for protein from the polymer surface.

\subsection{Preparation of polyurethane membranes}

The two-stage uncomplexed polyurethanes with three different equivalent ratios of polyol/ $\mathrm{H}_{12} \mathrm{MDI} /$ 1,4-BD (1/4/3, 1/8/7 and 1/12/11) were polymerized by solution polymerization method. Detailed procedures for polymerization had been reported in a previous publication [12]. All these dried membranes under study were $90 \mu \mathrm{m}$ thick. Complexed PUs were prepared by adding cupric chloride to the PU solutions with MDEA as chain extender and three different equivalent ratios of $\mathrm{HTPB} / \mathrm{H}_{12} \mathrm{MDI} / \mathrm{MDEA}(1 / 4 / 3$, $1 / 8 / 7$ and $1 / 12 / 11$, respectively). Cupric chloride with MDEA of $1 / 3$ or $1 / 4$ molar ratio content was added to the above three HTPB- $\mathrm{H}_{12}$ MDI-MDEA based PUs, respectively. The dried, complexed PU films were peeled from the plate after it had been kept for sometime in the refrigerator and then frozen for several hours. All these PUs were then put in an oven under vacuum at $70^{\circ} \mathrm{C}$ for $48 \mathrm{~h}$ for further degassing of the solvent residue. Finally, the samples were kept under a vacuum at room temperature for at least 5 days prior to the test. Complexed PU films of different compositions in this study are denoted, for instance, 11211-1/ $3 \mathrm{Cu}$ or $187-1 / 4 \mathrm{Cu}$. The numbers 11211 and 187 represent the equivalent ratio of $\mathrm{HTPB} / \mathrm{H}_{12} \mathrm{MDI} /$ $\mathrm{MDEA}=1 / 12 / 11$ and $1 / 8 / 7$, respectively. $1 / 3 \mathrm{Cu}$ or 
$1 / 4 \mathrm{Cu}$ means the addition of $1 / 3$ or $1 / 4$ molar ratio of cupric chloride with MDEA content to the PU composition, respectively.

\subsection{Infrared spectroscopy}

Infrared spectra of PU were obtained by using a JASCO FTIR-310E spectrometer. Spectra were collected at a resolution of $2 \mathrm{~cm}^{-1}$. The peak due to hydrogen-bonded $\mathrm{C}=\mathrm{O}$ stretching is centered at about $1700 \mathrm{~cm}^{-1}$ and that due to free $\mathrm{C}=\mathrm{O}$ stretching is centered at about $1717 \mathrm{~cm}^{-1}$, while the peak of bonded $-\mathrm{NH}$ stretching is at $3320 \mathrm{~cm}^{-1}$ and that of free $-\mathrm{NH}$ stretching is at $3442 \mathrm{~cm}^{-1}$. Hydrogenbonded carbonyl (or $-\mathrm{NH}$ ) bands will correspond to those groups that are in the interior of hard segments, while the free bands may correspond to those groups in the hard segment domains or in the soft domains or at the interface [13]. In these butadiene-containing PUs, hydrogen bonding occurs only between urethane segments since the carbonyl group in the urethane linkage and the urethane alkoxy oxygen are the only proton acceptors. The extent of the carbonyl group participating in hydrogen bonding is expressed by hydrogen bonding index (HBI), which is the relative absorbances of the hydrogen bonded carbonyl peak $\left(\mathrm{A}_{\mathrm{C}=\mathrm{O} \text {, bonded }}\right)$ to that of free hydrogen bonded carbonyl peak $\left(\mathrm{A}_{\mathrm{C}=\mathrm{O}}\right.$, free $)$ [14]. The frequency difference is defined as $\Delta \nu=\nu_{\mathrm{f}}-\nu_{\mathrm{b}}$, where $\nu_{\mathrm{f}}$ and $\nu_{\mathrm{b}}$ are the frequencies of maximum absorption for the free and hydrogen bonded - NH group, respectively. The frequency difference in the stretching frequency is considered as a measure of the strength of the hydrogen bond between molecules.

The infrared absorbance of carbonyl group measured by FTIR-ATR are calculated by the addition of the respective hydrogen bonded $\mathrm{C}=\mathrm{O}$ absorbance peak height and free $\mathrm{C}=\mathrm{O}$ absorbance peak height. The total absorbances of carbonyl group can be used as an indication of hard segment content on surface. The infrared absorption band of butadiene soft segment are trans $-1,4$ form at $972 \mathrm{~cm}^{-1}, 1,2$ form at $912 \mathrm{~cm}^{-1}$ and cis $-1,4$ form at $685 \mathrm{~cm}^{-1}$ [15]. The $\mathrm{C}=\mathrm{O} / \mathrm{C}=\mathrm{C}$ absorbance ratio is the ratio of total $\mathrm{C}=\mathrm{O}$ absorbance peak height with trans-1,4 form absorbance peak height. The $\mathrm{C}=\mathrm{O} / \mathrm{C}=\mathrm{C}$ absorbance ratio can then be used as the ratio of hard segment content to soft segment content. Larger value of $\mathrm{C}=\mathrm{O} / \mathrm{C}=\mathrm{C}$ ratio indicates that more hard segment content are dispersed on the surface.

\subsection{ESCA measurements}

ESCA data were obtained by using a Perkin-Elmer PHI 590 SAM/ESCA instrument, equipped with digital PDP 11/04 computer. The spectra were collected using exciting radiation from $\operatorname{MgK}_{\alpha}(h \nu=1253.6 \mathrm{eV})$ operated at a pressure lower than $5 \times 10^{-8} \mathrm{~Pa}, 250 \mathrm{~W}$. A survey scan (0-1000 eV binding energy) to determine the elemental composition of PU elastomer was conducted at an analyzer pass energy of $1000 \mathrm{eV}$. For high resolution studies, the pass energy was reduced to $25 \mathrm{eV}$. The atomic sensitivity factors (ASF) of the elements were taken into account to calculate atomic ratios.

\subsection{Contact angle measurement}

The contact angle of water was measured with a face contact angle meter CA-D type (Kyowa Interface Science Co. Ltd.). Sets of droplets (volume of approximately $1.8 \times 10^{-2} \mathrm{~cm}^{3}$ ) of water were placed on a membrane covered with fixing knob. The dimensions of the droplets were measured approximately $10 \mathrm{~s}$ after placing the droplets on the knob. The droplets must be small enough so that their shapes approximate a sphere. The contact angle was calculated by the following condition:

Contact angle $=2 \tan ^{-1}(h / r)$

where $h$ is the height of the spherical segment and $r$ is the radius of the spherical segment.

\subsection{Protein adsorption measurements}

The PU films with $8 \mathrm{~cm}^{2}$ surface area were immersed into CPBS buffer solution ( $0.01 \mathrm{M}$ sodium citrate, $0.01 \mathrm{M}$ sodium phosphate, $0.12 \mathrm{M}$ sodium chloride, $\mathrm{pH}$ 7.4) for $12 \mathrm{~h}$ [16]. Protein concentrations of albumin and fibrinogen were 1.0 and $0.2 \mathrm{mg} / \mathrm{ml}$, respectively, in CPBS buffer solution. The film surface was then quickly blotted with absorbent paper to remove surface buffer solution. The films were then filled with $2 \mathrm{ml}$ of protein solution at $30^{\circ} \mathrm{C}$ for $1 \mathrm{~h}$. After desorption, the films were then rinsed with deionized water. The absorbed proteins were desorbed 
with solution of $1 \%$ Triton $\mathrm{X}-100$ and $1 \%$ dodecyl sodium sulfate in $0.01 \mathrm{~N} \mathrm{NaOH}$ at $30^{\circ} \mathrm{C}$ with agitating at $100 \mathrm{rpm}$ for $1 \mathrm{~h}$. Afterwards buffer solution with $\mathrm{pH}$ 9.3, which compose of both $0.05 \mathrm{M}$ boric acid and $\mathrm{KCl}$, was added into the desorbed proteins. $0.5 \mathrm{ml}$ fluorescamine solution with a $3: 2$ volume ratio in acetone $(20 \mathrm{mg} / 100 \mathrm{ml})$ were added to the mixture with vigorous stirring. The protein quantity was determined by a fluorescence spectrophotometer (Hitachi, F-2000) and the fluorescence intensity was measured at $392 \mathrm{~nm}$ with excitation and at $491 \mathrm{~nm}$ with emission. Lower F/A molar ratio means more adsorption of albumin or less fibrinogen deposition or both possessed on the polymer surface.

\subsection{Differential scanning calorimeter}

A du pont 9000 instrument was used for DSC measurement, using liquid nitrogen for cooling and with a heating rate of $10^{\circ} \mathrm{C} / \mathrm{min}$ in temperature range between -120 and $150^{\circ} \mathrm{C}$. Glass transition temperature of soft segment $\left(T_{\mathrm{gs}}\right)$ and hard segment $\left(T_{\mathrm{gh}}\right)$ were measured and hence, glass transition temperature difference $\left(\Delta T_{\mathrm{g}}\right)$ between $T_{\mathrm{gh}}$ and $T_{\mathrm{gs}}$ was calculated.

\section{Result and discussion}

\subsection{ESCA measurement}

In order to examine the $\mathrm{C}=\mathrm{O} / \mathrm{C}=\mathrm{C}$ ratio on the air face composition, ESCA analysis was used to calculate the ratio of oxygen to carbon atom $(\mathrm{O} / \mathrm{C})[17,18]$. The peak of the oxygen element, which appears at $534 \mathrm{eV}$ on ESCA spectra, indicates that the hard segment is on the PU polymer surface, while that of carbon element appears at $287 \mathrm{eV}$, and this means that the soft segment is on the surface. The peak area ratio between oxygen and carbon element is expressed by $\mathrm{O} / \mathrm{C}$ ratio and can be used as the ratio of hard segment content to soft segment content on the surface. The larger ratio of $\mathrm{O} / \mathrm{C}$ ratio indicates that more hard segment are dispersed on the polymer surface. Fig. 1 shows that $\mathrm{O} / \mathrm{C}$ ratio increases as the increase of $\mathrm{C}=\mathrm{O} / \mathrm{C}=\mathrm{C}$ ratio. The increase of $\mathrm{C}=\mathrm{O} / \mathrm{C}=\mathrm{C}$ ratio and the $\mathrm{O} / \mathrm{C}$ ratio both mean that more hard segment content are dispersed on the polymer surface. The result indicates that the $\mathrm{C}=\mathrm{O} / \mathrm{C}=\mathrm{C}$ ratio can be used to investigate the change of surface composition.

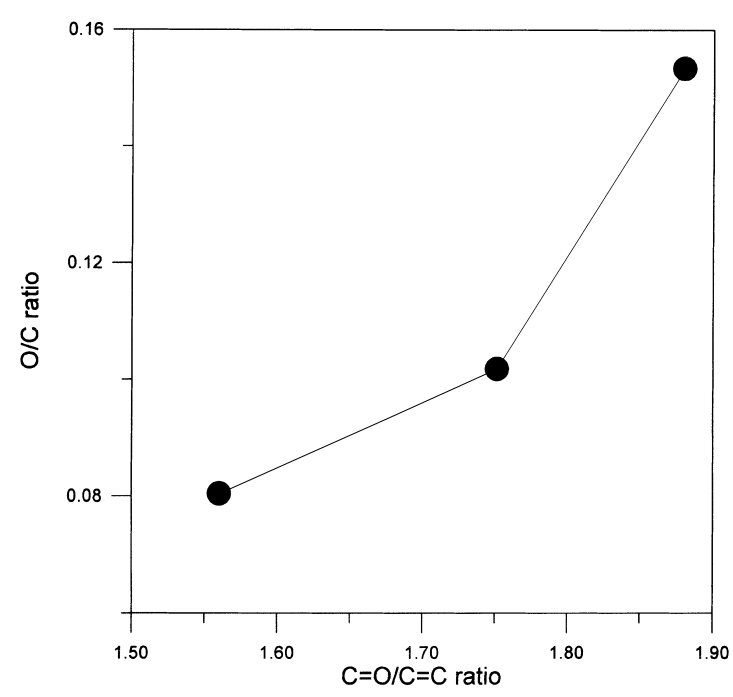

Fig. 1. Relationship between $\mathrm{O} / \mathrm{C}$ ratio and $\mathrm{C}=\mathrm{O} / \mathrm{C}=\mathrm{C}$ ratio of uncomplexed PUs.

\subsection{Contact angle measurement}

The water contact angle experiment was used to estimate the surface hydrophilicity. A higher contact angle value indicates less hydrophilicity, suggesting the higher nonpolar HTPB soft segment dispersed on these butadiene-containing PUs polymer surface. The results are shown in Tables 1 and 2. Three polyols,

Table 1

Contact angle and F/A molar ratio of different polyol-based uncomplexed PUs with equivalent ratio of 1/8/7

\begin{tabular}{llll}
\hline Type of polyol & HTPB & PPG & PBA \\
\hline Contact angle & 85 & 63 & 55 \\
F/A molar ratio & 0.1452 & 0.2213 & 0.2479 \\
\hline
\end{tabular}

HTPB: Hydroxyl-terminated polybutadiene; PPG: Polyoxypropylene glycol; PBA: Polybutylene adipate glycol.

Table 2

Contact angle of HTPB-based PUs with different hard segment content and cupric chloride content

\begin{tabular}{llll}
\hline $\begin{array}{l}\text { Molar ratio of cupric } \\
\text { chloride content }\end{array}$ & 0 & $1 / 4$ & $1 / 3$ \\
\hline H143 & 88 & 93 & 84 \\
H187 & 81 & 87 & 82 \\
H11211 & 76 & 83 & 71 \\
\hline
\end{tabular}


Table 3

Solubility parameter of raw materials

\begin{tabular}{llllll}
\hline Materials & HTPB & $\mathrm{H}_{12} \mathrm{MDI}$ & $1,4-\mathrm{BD}$ & PPG & PBA \\
\hline Solubility parameter $\left(\mathrm{cal}^{1 / 2} / \mathrm{cm}^{3 / 2}\right)$ & 8.67 & 8.98 & 11.00 & 9.14 & 9.46 \\
\hline
\end{tabular}

PBA, PPG and HTPB were used to synthesize different types of PU for contact angle and protein tests. As shown in Table 1, the contact angle falls in the following sequence: HTPB > PPG > PBA. The surface of HTPB-based PU possesses the highest contact angle value, and this may be because the polarity of HTPB is the lowest one among these three polyols, as shown in Table 3. In general, the air-polymer interface possesses more nonpolar soft segment, while that on the glass face has more polar hard segment content [6,11]. On the other hand, hydrogen bonding (i.e. intermolecular interaction) of these butadiene-containing PUs occurs only between urethane segments. From the above two explanations of polarity and intermolecular interaction, soft segment of HTPB will be easily dispersed on the polymer surface than the other two polyols based PUs. While the results of Table 2 are explained in Section 3.5.

\subsection{Effect of polyol type}

Table 1 shows that the F/A molar ratio decrease in the following sequence: HTPB $<$ PPG $<$ PBA. The reason may be that more HTPB soft segment dispersed on the surface than the other two polyols based PUs. The reason is that the surface of HTPB-based PU is more hydrophobic than the other two types of PU, which has been explained in Section 3.2. By the way, it has been reported that alkyl-grafted SPUs or the introduction of long alkyl side chain onto a PU have been shown to reduce platelet deposition and enhance in vitro albumin adsorption $[18,19]$. So that more soft segment dispersed on the polymer surface than the other two types of PUs which may be the reason for the lowest F/A molar ratio of HTPB-based PU.

\subsection{Effect of hard segment content}

Three different equivalent ratios, $1 / 4 / 3,1 / 8 / 7$ and $1 /$ 12/11, of HTPB-H ${ }_{12}$ MDI-1,4-BD based PUs with hard segment content of 33.08, 50.56, 60.79 wt.\% were prepared. Fig. 2 shows that the F/A molar ratio and $\mathrm{C}=\mathrm{O} / \mathrm{C}=\mathrm{C}$ ratio are increased as the increase of hard segment content. The enlargement of hard segment aggregation and the restriction of soft segment, moving toward polymer surface, are all increased as the increase of hard segment content. The overall composition distribution is more even in accordance with the increase of hard segment content. On the other hand, Fig. 3 shows that the HBI value increases as the hard segment content increases. This may indicate that more hard segments are aggregated together and the phase homogeneity increased, and hence the surface composition will be rich in hard segment as the hard segment content increases. Films with high hard segment content will have a low affinity for albumin adsorption (or high F/A molar ratio) due to the increase of $\mathrm{C}=\mathrm{O} / \mathrm{C}=\mathrm{C}$ ratio or hard segment content on the surface as explained in Section 3.3.

\subsection{Effect of cupric chloride addition}

HTPB-H 12 MDI-MDEA based PU complexes with three equivalent ratio of 1/4/3,1/8/7 and 1/12/11 were prepared by complexing cupric ion with the tertiary amine of MDEA. It was due to poor film formation; our studies were restricted to film containing cupric chloride lower than a $1 / 2 \mathrm{CuCl} 2$ to MDEA molar ratio. The film property of the ones containing lower than a $1 / 5$ molar ratio of cupric ions were essentially the same as the one without any cupric ion complexation. As was shown in Fig. 4, the F/A molar ratio of all three types of PU films containing 1/4CuCl2/MDEA molar ratio were lower than those of zero cupric chloride content, while the film with $1 / 3$ molar ratio of cupric chloride had an increased F/A molar ratio.

The explanation may be that the cupric ion interacts with the tertiary amine of MDEA as well as the carbonyl and secondary amine in urethane linkage [20]. The addition of cupric chloride may destroy the hydrogen bonding between hard segments. Hydrogen bonding of PU films containing 1/4 molar ratio of cupric chloride may only has little disruption and the intermolecular attraction between hard and soft seg- 


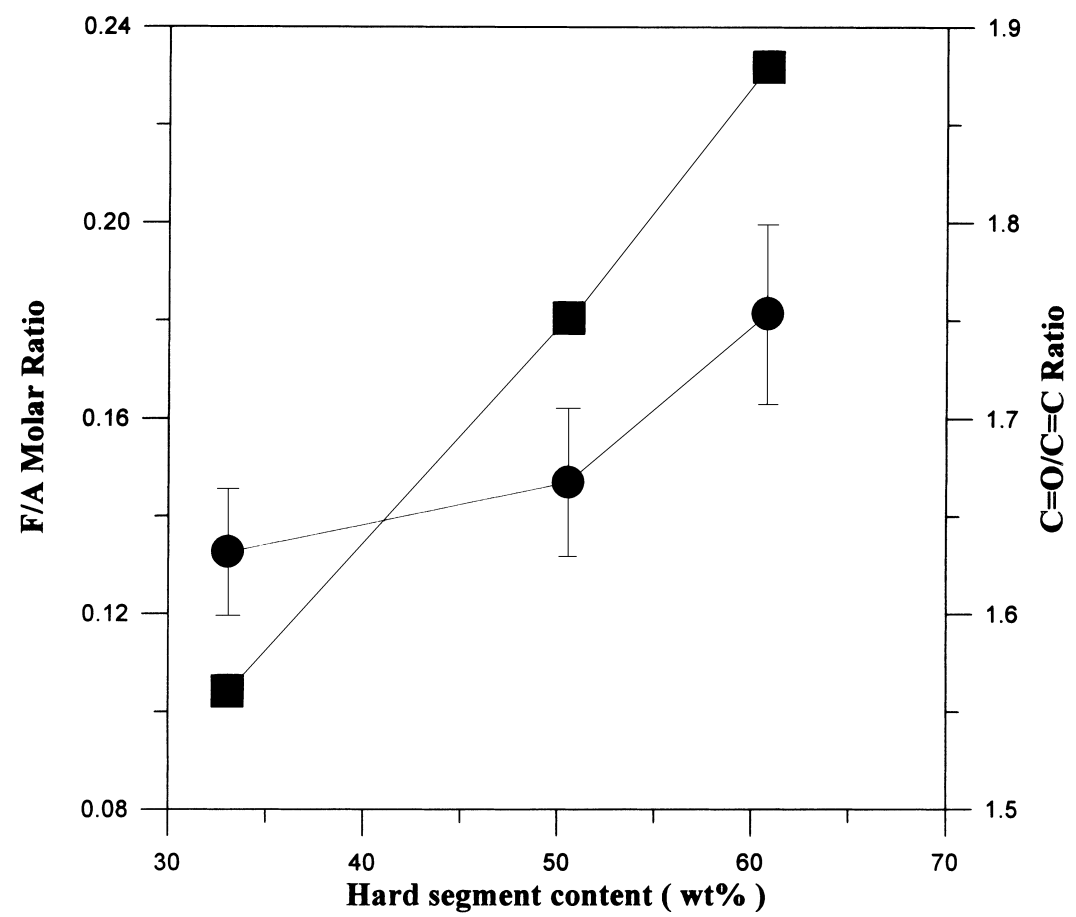

Fig. 2. Effect of hard segment content on the F/A molar ratio $(\mathbf{O})$ and $\mathrm{C}=\mathrm{O} / \mathrm{C}=\mathrm{C}$ ratio $(\boldsymbol{\square})$ of uncomplexed PUs.

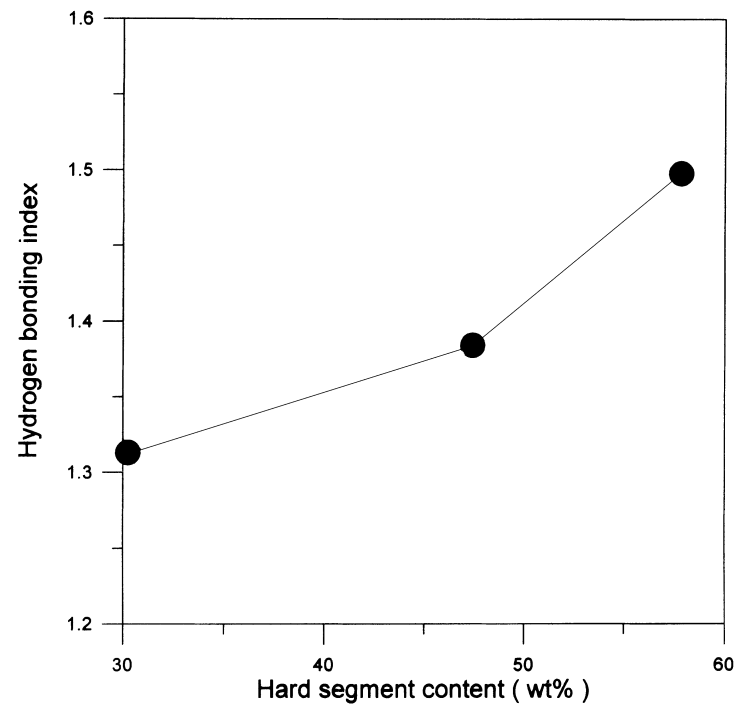

Fig. 3. Effect of hard segment content on the HBI values of uncomplexed PUs.

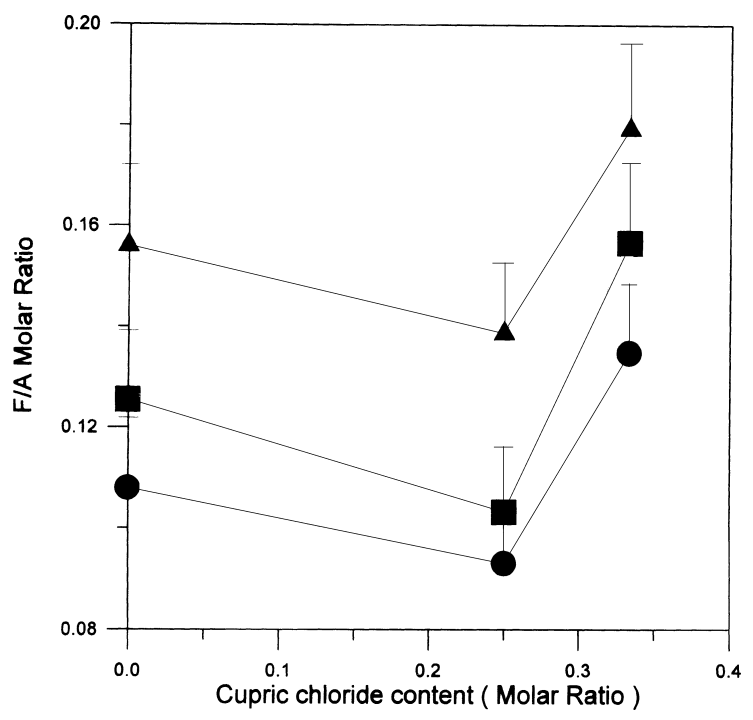

Fig. 4. Effect of cupric chloride content on the F/A molar ratio of PUs with different equivalent ratio. $(\mathbf{O}) 1 / 4 / 3(\boldsymbol{\square}) 1 / 8 / 7(\mathbf{\Delta}) 1 / 12 /$ 11. 


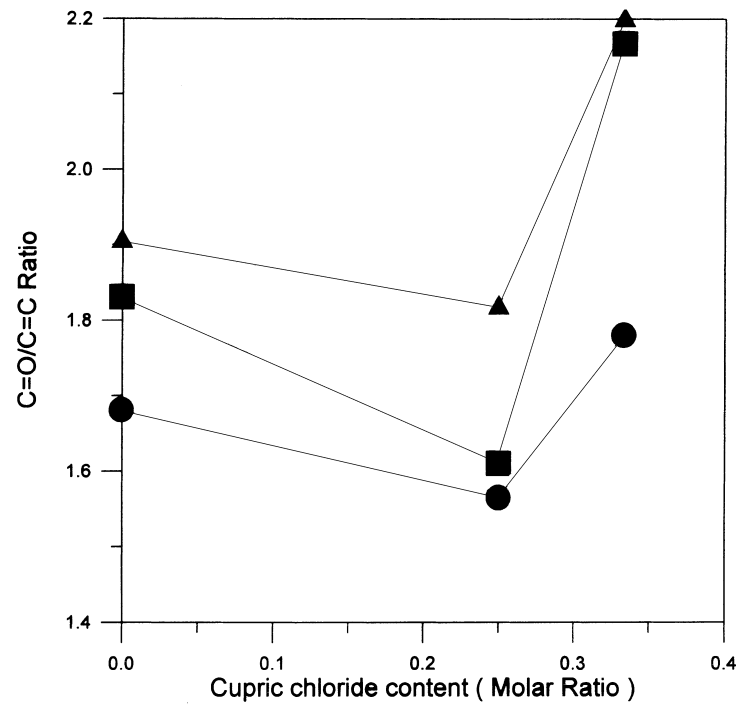

Fig. 5. Effect of cupric chloride content on the $\mathrm{C}=\mathrm{O} / \mathrm{C}=\mathrm{C}$ ratio of

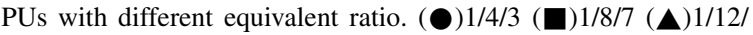
11.

ment will increase due to the ionic bonding of cupric ion and hard segment. The phase separation between hard and soft segment of PU films containing 1/4 molar ratio of cupric chloride and the migration of soft segment toward polymer surface are all increased due to the increase of intermolecular attraction between hard and hard segments. While the destruction of hydrogen bonding and free $\mathrm{C}=\mathrm{O}$ or $\mathrm{N}-\mathrm{H}$ groups participation in the soft segment is increased, just as the film containing $1 / 3 \mathrm{CuCl}_{2} / \mathrm{MDEA}$ molar ratio. Then the phase homogeneity and hard segment content (i.e. $\mathrm{C}=\mathrm{O} / \mathrm{C}=\mathrm{C}$ ratio) on polymer surface of PUs with $1 / 3$ molar ratio of cupric chloride are all increased. As shown in Fig. 5, $\mathrm{C}=\mathrm{O} / \mathrm{C}=\mathrm{C}$ ratio on the surface has a minimum value as the PUs containing $1 / 4 \mathrm{CuCl}_{2} / \mathrm{MDEA}$ molar ratio. The change of protein adsorption property of these PU complexes can be investigated by the variation of the $\mathrm{C}=\mathrm{O} / \mathrm{C}=\mathrm{C}$ ratio. Therefore, the addition of cupric ion will effect the binding between hard segments and subsequently induce a variation of hard segment dispersed or protein adsorption on the polymer surface. As discussed in Section 3.4, the decrease of long chain alkyl group (e.g. HTPB soft segment) dispersed on the surface of the film containing $1 / 3 \mathrm{CuCl}_{2} / \mathrm{MDEA}$ molar ratio may be the reason for the increase of F/A absorption molar ratio.
Table 2 shows that the variation of contact angle value has the reverse trend as the $\mathrm{C}=\mathrm{O} / \mathrm{C}=\mathrm{C}$ does. It indicates that the polarity of complexed PUs with $1 / 4 \mathrm{CuCl}_{2} / \mathrm{MDEA}$ molar ratio possess the highest contact angle value than the other two types of PUs. This may mean that complexed PUs with $1 / 4 \mathrm{CuCl}_{2} / \mathrm{MDEA}$ molar ratio have the highest nonpolar HTPB soft segment content dispersed on the surface, which is in agreement with the result shown in Fig. 5.

\subsection{Characterization of $P U$ complex}

\subsubsection{Frequency difference and shiftment}

Frequency difference and shiftment were utilized in this study to discuss the effect of cupric chloride content on the intermolecular interactions and morphology change. Coleman and coworkers [21] have used frequency difference between hydroxyl groups and those of hydrogen bonded hydroxyl groups as a measure of the average strength of the intermolecular interactions. In this respect the average strength of the hydrogen bonds (or $\Delta \nu$ ) between intermolecules are decreased as the cupric chloride content increased and there is a sharp decrease of frequency difference as the $\mathrm{CuCl}_{2}$ content exceeds $1 / 4$ molar ratio as shown in Fig. 6. The explanation may be that the destruction of

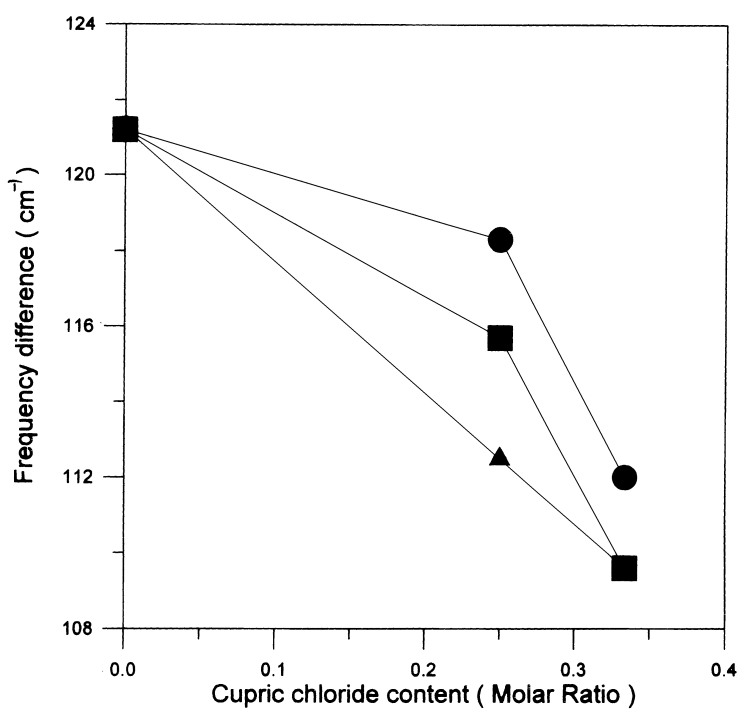

Fig. 6. Effect of cupric chloride content on the frequency difference of PUs with different equivalent ratio. (O)1/4/3 (ם)1/ $8 / 7$ (A) $1 / 12 / 11$. 
Table 4

Wavenumber of $\mathrm{N}-\mathrm{H}$ and $\mathrm{C}=\mathrm{O}$ groups absorption

\begin{tabular}{lll}
\hline Composition & $\begin{array}{l}\text { Wavenumber } \\
\left(\mathrm{cm}^{-1}\right) \text { of bonded } \\
\mathrm{N}-\mathrm{H} \text { group }\end{array}$ & $\begin{array}{l}\text { Wavenumber } \\
\left(\mathrm{cm}^{-1}\right) \text { of bonded } \\
\mathrm{C}=\mathrm{O} \text { group }\end{array}$ \\
\hline 143 & 3320.8 & 1700.9 \\
$143-1 / 4 \mathrm{Cu}$ & 3323.7 & 1702.5 \\
$143-1 / 3 \mathrm{Cu}$ & 3330.4 & 1704.8 \\
187 & 3320.8 & 1700.9 \\
$187-1 / 4 \mathrm{Cu}$ & 3326.3 & 1701.8 \\
$187-1 / 3 \mathrm{Cu}$ & 3332.4 & 1702.8 \\
11211 & 3320.8 & 1700.9 \\
$11211-1 / 4 \mathrm{Cu}$ & 3329.5 & 1702.2 \\
$11211-1 / 3 \mathrm{Cu}$ & 3332.4 & 1702.8 \\
\hline
\end{tabular}

hard segment interaction increased with the increase of $\mathrm{CuCl}_{2}$ content.

Table 4 shows that the extent of wavenumber shift of $\mathrm{C}=\mathrm{O}$ and $\mathrm{N}-\mathrm{H}$ groups increases as the increase of cupric chloride content. Since the cupric ion interacts with the tertiary amine of MDEA as well as the carbonyl and secondary amine in urethane linkage. Upon complexation, the energy and force constant of the $\mathrm{N}-\mathrm{H}$ or $\mathrm{C}=\mathrm{O}$ groups absorption increases and the absorption band is therefore shifted to a higher frequency as the addition of cupric chloride.

\subsubsection{Differential scanning calorimeter}

Figs. 7 and 8 show that the glass transition temperature of soft segment $\left(T_{\mathrm{gs}}\right)$ and hard segment $\left(T_{\mathrm{gh}}\right)$ increased as the cupric chloride content increased. The increase of $T_{\mathrm{gs}}$ indicated that the decrease of soft segment mobility, which is due to more hydrogen bonded of hard segment dispersed in the soft segment. The number of $\mathrm{C}=\mathrm{O}$ or $\mathrm{N}-\mathrm{H}$ group of hard segment dispersed in the soft segment increases as the increase of cupric chloride content. Subsequently the flexibility of soft segment decreased and hence the increase of $T_{\mathrm{gs}}$. While the increase of $T_{\mathrm{gh}}$ indicates that the increase of hard segment content will increase the intermolecular attraction and the enlargement of hard domain. As the cupric chloride content increased, the binding between hard segments increased and hence the increase of $T_{\mathrm{gh}}$.

The effect of cupric chloride content on the morphology change may be evidenced by the difference of glass transition temperature between $T_{\mathrm{gh}}$ and $T_{\mathrm{gs}}$ $\left(\Delta T_{\mathrm{g}}\right)$. Fig. 9 shows that $\Delta T_{\mathrm{g}}$ decreases as the cupric

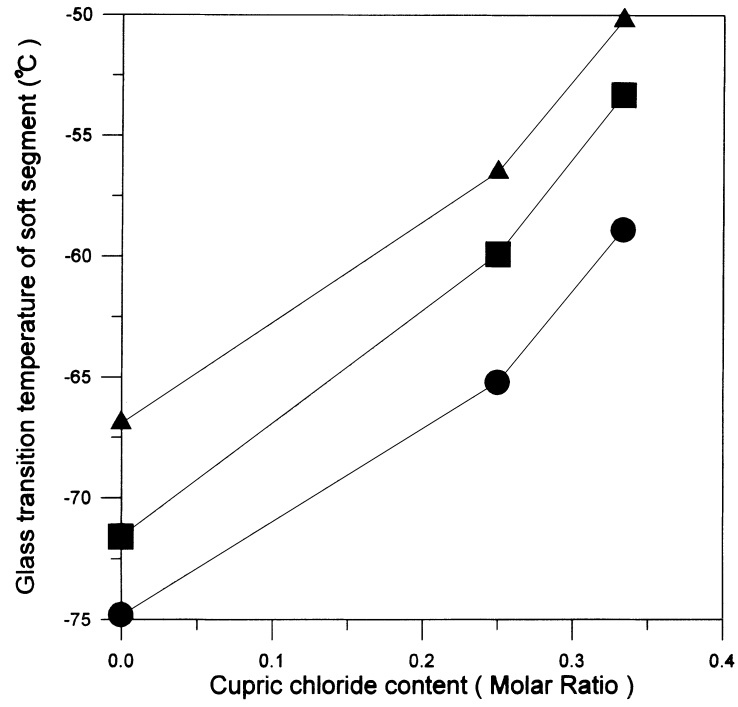

Fig. 7. Effect of cupric chloride content on the glass transition temperature of soft segment of PUs with different equivalent ratio. (O) $1 / 4 / 3(\boldsymbol{\square}) 1 / 8 / 7(\boldsymbol{A}) 1 / 12 / 11$.

chloride content increases. The reduction in $\Delta T_{\mathrm{g}}$ indicates the increase of microphase homogeneity, i.e. the amount of hard segment dispersed in soft segment region increased.

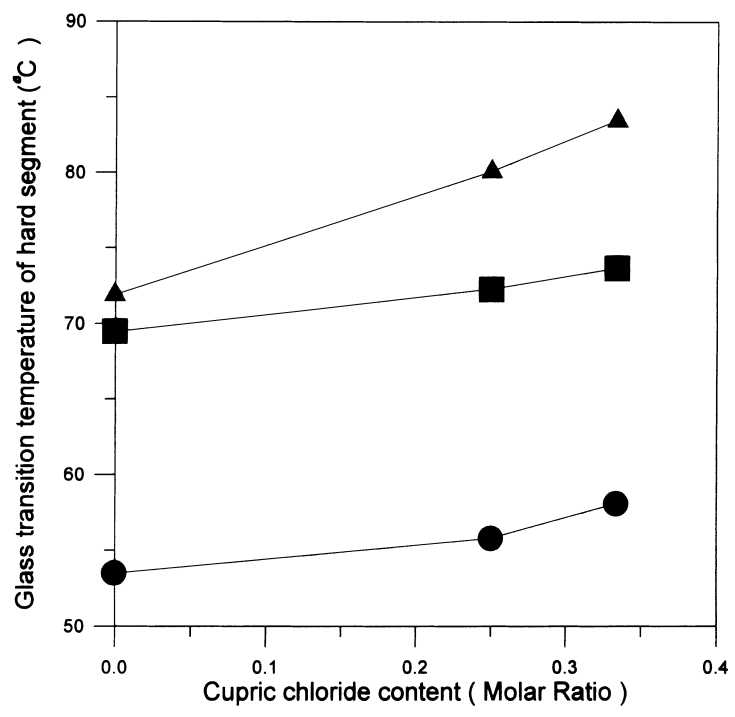

Fig. 8. Effect of cupric chloride content on the glass transition temperature of hard segment of PUs with different equivalent ratio. 


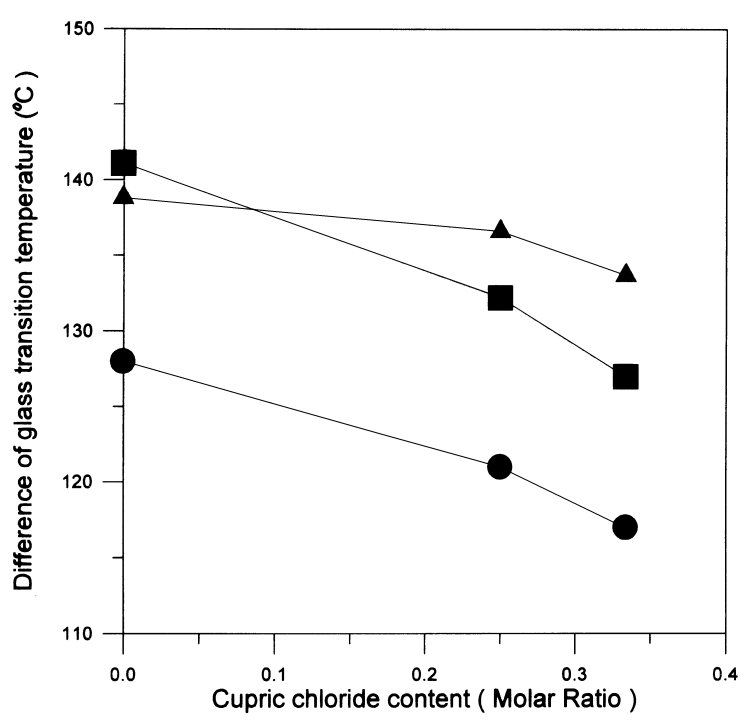

Fig. 9. Effect of cupric chloride content on the difference of glass transition temperature of PUs with different equivalent ratio. (O)1/ $4 / 3$ (ם) $1 / 8 / 7$ (A) $1 / 12 / 11$.

\section{Conclusions}

The increase of hard segment content of PU composition will increase the aggregation of hard segment domain and hard segment content on the surface and hence, increase the F/A molar ratio. The F/A molar ratios of complexed PUs decrease to a minimum as the film with $1 / 4$ molar ratio of cupric chloride and then increase as the cupric chloride content increase further. All the above results can be explained by the increase of soft segment content and contact angle or the decrease of $\mathrm{C}=\mathrm{O} / \mathrm{C}=\mathrm{C}$ ratio on the polymer surface. This study imply that HTPB-based PUs possess lower F/A molar ratios and a superhydrophobic surface and be used as biomaterials for further study on blood compatibility.

\section{References}

[1] H.Y.K. Chuang, In situ immunoradiometric assay of fibrinogen adsorbed to artificial surfaces, J. Biomed. Mater. Res. 18 (1984) 547.

[2] Y. Sisdo, M. Ito, Y. Imanishi, Platelet adhesion onto protein coated and uncoated polyetherurethaneurea having tertiary amino groups in substituents and its derivative, J. Biomed. Mater. Res. 23 (1994) 191.

[3] A.S. Hoffman, Biomedical applications of plasma gas discharge processes: a tutorial presentation, Polym. Mat.
Sci. Eng. 56 (1987) 699.

[4] P.E. Fabienne, L. Gilbert, J.C. Brosse, Plasma modification of cellulose derivatives as biomaterials, J. Appl. Polym. Sci. 44 (1992) 1513.

[5] J.H. Silver, K.B. Lewis, B.D. Ratner, S.L. Cooper, Effect of polyol type on the surface structure of sulfonate-containing polyurethanes, J. Biomed. Mater. Res. 27 (1993) 735.

[6] K. Tanaka, T.S. Yoon, A. Takahara, T. Kajiyama, Ultrathinning induced surface phase separation of polystyrene/poly(vinyl methylether) blend film, Macromolecules 28 (1995) 934.

[7] A.S. Hoffman, Blood-biomaterial interactions: An overview in biomaterials: interfacial phenomena and applications, ACS Adv. Chem. Ser. 3 (1982) 199.

[8] W.G. Pitt, S.L. Cooper, Albumin adsorption on alkyl chain derivatized polyurethanes: I. The effect of C-18 alkylation, J. Biomed. Mater. Res. 22 (1988) 359.

[9] J.L. Brash, S. Unival, Dependence of albumin-fibrinogen simple and competitive adsorption on surface properties of biomaterial, J. Polym. Sci. 66 (1979) 377.

[10] C.Y. Shih, J.Y. Lai, Polyvinyl alcohol plasma deposited nylon 4 membrane for hemodialysis, J. Biomed. Mater. Res. 27 (1993) 983.

[11] Y.J. Li, N. Nakamura, Y.F. Wang, M. Kodama, T. Nakaya, Synthesis and hemocompatibilities of new segmented polyurethanes and poly(urethane urea)s with poly(butadiene) and phosphatidylcholine analogues in the main chains and long-chain alkyl groups in the side chains, Chem. Mater. 9 (1997) 1570.

[12] S.L. Huang, J.Y. Lai, On the gas permeability of hydroxyl terminated polybutadiene based polyurethane membrane, J. Membrane Sci. 105 (1995) 137.

[13] M.M. Coleman, D.J. Skrovanek, J. Hu, P.C. Painter, Hydrogen bonding in polymer blends. 1. FTIR studies of urethane-ether blends, Macromolecules 21 (1988) 59.

[14] R.W. Seymour, G.M. Estes, S.L. Cooper, Infrared studies of segmented polyurethane elastomers: Hydrogen bonding, Macromolecules 3 (1970) 579.

[15] T.M. Don, W.Y. Chiu, K.H. Hsieh, The thermal aging of filled PU, J. Appl. Polym. Sci. 43 (1992) 2193.

[16] D.R. Absolom, W. Zingg, A.W. Neumann, Protein adsorption to polymer particles: role of surface properties, J. Biomed. Mater. Res. 21 (1987) 161.

[17] J.Y. Lai, Y.L. Deng, J.K. Chen, L.Y. Yuan, Y.Y. Lin, S.S. Shyu, Peel strength improvement of silicone rubber film by plasma pretreatment followed by graft copolymerization, J. Adhesion Sci., Technol. 9 (1995) 813.

[18] R. Rahman, B.D. Ratner, Synthesis and ESCA surface studies of octadecyl chain-extended polyurethanes, J. Polym. Sci.: Part A: Polym. Chem. 27 (1989) 2673.

[19] W. Marconi, A. Galloppa, A. Martinelli, A. Piozzi, New polyurethane compositions able to bond high amounts of both albumin and heparin, Part I, Biomaterials 16 (1995) 449.

[20] M. Rutkowska, A. Eisenberg, Ion-dipole interactions in polyether polyurethane-styrene ionomer blends, J. Appl. Polym. Sci. 33 (1987) 2833.

[21] E.J. Moskala, D.F. Varnell, M.M. Coleman, Concerning the miscibility of poly(vinyl phenol) blends FTIR study, Polymer 26 (1985) 228. 